\title{
INEQUALITIES INVOLVING LOGARITHMIC MEAN OF ARBITRARY ORDER
}

\author{
EDWARD NEUMAN AND JÓZSEF SÁNDOR
}

\begin{abstract}
Inequalities involving logarithmic mean of arbitrary order are obtained. These results are derived from the Lazarević and Causa-Huygens inequalities for hyperbolic functions. Some inequalities for the weighted sums of powers are also utilized. In particular cases obtained results simplify to known inequalities for the logarithmic mean of a low order.
\end{abstract}

Mathematics subject classification (2010): Primary: 26D15. Secondary: 26D05.

Keywords and phrases: Logarithmic mean of arbitrary order, power means, Lazarević and CusaHuygens inequalities, hyperbolic functions, inequalities.

\section{REFERENCES}

[1] B. C. CARLSON, The logarithmic mean, Amer. Math. Monthly 79 (1972), 615-618.

[2] D. S. Mitrinović, Analytic Inequalities, Sprinder-Verlag, Berlin, 1970.

[3] E. Neuman, Inequalities involving logarithmic, power and symmetric means, J. Inequal. Pure Appl. Math. 6, 1 (2005), Article 15 (electronic).

[4] E. Neuman, Inequalities for the Schwab-Borchardt mean and their applications, J. Math. Inequal. 5 (2011), 601-609.

[5] E. Neuman, Inequalities for weighted sums of powers and their applications, Math. Inequal. Appl., 15, 4 (2012) 995-1005.

[6] E. Neuman, J. SÁndor, Inequalities involving Stolarsky and Gini means, Math. Pannon. 14, 1 (2003), 29-44.

[7] E. Neuman, J. SÁndor, On the Schwab-Borchardt mean, Math. Pannon. 14, 2 (2003), 253-266.

[8] E. Neuman, J. SÁndor, On certain means of two arguments and their extensions, Int. J. Math. Math. Sci. 2003, No. 16, 981-993.

[9] E. Neuman, J. SÁNDOR, On some inequalities involving trigonometric and hyperbolic functions with emphasis on Cusa-Huygens, Wilker and Huygens inequalities, Math. Inequal. Appl. 13, 4 (2010), 715-723.

[10] Zs. PÁLES, Inequalities for differences of powers, J. Math. Anal. Appl. 131 (1988), 271-281.

[11] J. PeČarić, F. Proschan, Y. L. Tong, Convex Functions, Partial Orderings and Statistical Applications, Academic Press, Boston, 1992.

[12] J. SÁNDOR, On refinements of certain inequalities for means, Arch. Math. (Brno) 31 (1995), 279-282.

[13] J. SÁNDOR, On certain inequalities for means II, J. Math. Anal. Appl. 199 (1996), 629-635.

[14] J. SÁNDOR, On the arithmetic-geometric mean of Gauss, Octogon Math. Mag. 7 (1999), 108-115.

[15] K. B. Stolars Ky, Generalizations of the logarithmic mean, Math. Mag. 48, 2 (1975), 87-92. 